Адрес статьи / To link this article: http://cat.ifmo.ru/ru/2019/v4-i1/174

\title{
Влияние цифровых средств коммуникации на качество жизнедеятельности, удовлетворенность жизнью и ощущение включённости пожилых людей
}

\author{
Е.В. Рыбакова, Р.М. Султанова, Г.А. Гаязова \\ ФГБОУ ВО Башкирский Государственный университет, Россия \\ evrybakoval9@mail.ru, sultanovar@list.ru, gulshat_g@bk.ru
}

\begin{abstract}
Аннотация. Приобщение пожилых граждан к интернет-коммуникации неравнозначно процессам освоения цифрового пространства более младших, более активных, мобильных поколений и имеет свои как рисковые, так и ресурсные перспективы. По результатам исследования, проведённого в Республике Башкортостан, раскрываются некоторые особенности жизнедеятельности наших пожилых современников, как отказавшихся от системного присутствия интернет-технологий в своём обиходе, так и включившихся в эту существенную сферу социальных отношений. Авторы полагают важным признаком эволюционного характера обозначившуюся тенденцию к совпадению информационного преобразования социума с изменением состояния человеческой популяции - применительно к целевым группам данного исследования это и осознаваемый запрос на информационнотехнологическое соответствие занятости, и скрытая нуждаемость в интернет-включённости, и жизненное благоприятствование в условиях адресного технологического сопровождения старшей части населения.
\end{abstract}

Ключевые слова: включённость, пожилые, жизнедеятельность, технологии, удовлетворённость

С одной стороны, конечно, интернет-включённость априори обогащает жизнедеятельность и представляет ряд возможностей самого разного плана, как бытовых - так и социальноправовых, культурных, личностных [1]. Хотя значительная часть населения по-прежнему представляет интернет как достаточно зловредную стихию.

С другой - представители старших поколений, в том числе одинокие, ранее обходились без информационных технологий и, в целом, в различной степени обходятся. Многие граждане, участвовавшие в проекте, до инвалидизации и достижения пожилого возраста проявлявшие склонность к активному образу жизни, активной жизненной позиции, осознанно выбирали ограниченный порядок освоения электронных устройств - например, только мобильную связь и электронную книгу с произведениями классических и современных авторов - и настойчиво придерживались своего решения. Наблюдали мы такой вариант и в группах с выраженной сенсорной недостаточностью, в том числе слепотой и глухотой. Иногда такая позиция отражает и мнение значимых для граждан авторитетов, как близко живущих, так и территориально, социально дистанцированных - вплоть до телеперсонажей и героев книг. 
Наши студенческие и волонтёрские исследовательские группы, представители пожилого населения изучали качество социального самочувствия, удовлетворенности, динамику жизнедеятельности и самостоятельности одиноко живущего пожилого человека - или дистанцированного частично, временно, периодически.

Даже в условиях благоприятного индивидуализированного сопровождения, усиленного привлечением волонтёров, разработки специальных социализирующих средств [2] сообразно индивидуальным потребностям и перспективно ориентированным склонностям, наступает момент, когда пожилой человек заметно отдаляется от социума, от своих собственных стандартов жизнедеятельности, накапливая социально негативные привычки и представления.

Примечательно, что в данном случае эти изменения как раз нередко наступают не постепенно, а достаточно резко и продолжают нарастать с видимой неостановимостью. Совпадение этих процессов с изменением неврологического статуса граждан имеет двоякую природу - как согласно литературным источникам, так и по наблюдениям наших исследователей. Насколько первичны здесь мозговые явления - насколько социально-деятельностная депривация, решить бывает затруднительно, что диалектически сообразно.

Проводимые опросы, анкетирование показывают, что зачастую участники наших программ сопровождения в той или иной мере осознают направленность и перспективу происходящих в них изменений, не имея сил и желания предотвратить снижение качества жизнедеятельности и включённости. Увещевания, усилия, настояние других людей воспринимаются ими в значительной степени формально, нарастают уловки уклонения от деятельного участия в предлагаемых мероприятиях и усилиях, а также обесценивания и негативизации намерений доброжелателей.

Комплексное наблюдение конфликтной, осудительной, депрессивной готовности обнаруживает и очаги социально позитивной саморегуляции, пожилой сопровождаемый будто подсказывает средства, приёмы, которые могут купировать негативные настроения, излишнюю нервозность и подозрительность, темы, которые не вызовут повышенной драматизации и истеричности.

Как объясняют пожилые представители интеллектуальных профессий, активной социальной жизни, иногда закрепляются огрублённые реакции на внешний мир и внутреннее беспокойство, позволяющее достичь эмоциональной и иной разрядки, но эти реакции могут быть заменены на социально приемлемые либо темпорально распределены.

В течение многих лет в Башкирском Государственном Университете, на базе Белорецкой Педагогической Гостиной [3] проводится работа по организации общения, досуга пожилых одиноко живущих людей с учётом их потребностей и пожеланий, с формированием более вариативных, развивающихся запросов, предупреждающих социальную апатию, энтропию жизнеспособности, акцентирование личности на деструктивных, драматичных либо упаднических настроениях. Помимо удовлетворения обиходных пожеланий (например, при повышенном треморе хотят молоко в более устойчивой коробке, ослепшие - более удобно открываемой и закрываемой и т. д.), толерантности к взглядам и грамотного сопровождения капризов, конфликтов, перепадов настроения, активисты инициируют творческую, конкурсную, общественную активность подопечных, способствуют возобновлению, восстановлению утрачивающихся навыков бывшей профессиональной деятельности, организуют на дому приёмы по интересам и клубного типа, формируют группы по интересам и модули обмена опытом.

Ранее люди, подобным образом включенные в социальную жизнь, ощущающие свою необходимость сообразно индивидуальные особенностям, в основном долгое время гармонично осуществляли доступную жизнедеятельность, постепенно утрачивая навыки и жизненные позиции, вкус к деятельности и силы.

Однако ныне мы наблюдаем более выраженные энтропийные тенденции среди пожилых граждан $[4,5]$, в чьём пакете социально-личностных благ недостаёт столь недавно включённого в обиход человечества компонента - информационно-технологического инструментария. Столь же настоятельно наблюдаем мы ныне корреляцию информатизации цивилизации с изменением нервно-психического статуса подрастающих (и, некоторым образом, уже и подросших) поколений. 
Наблюдаемая нами картина, несомненно, будет ещё развиваться и, возможно, ключом к особенностям, потребностям и приоритетам маленьких граждан $[6,7,8]$ станут реалии, выявляемые в процессе изучения и сопровождения особых потребностей и информационных барьеров у пожилых людей.

Описанные явления относятся даже к тем пожилым гражданам, у которых есть родственники, пусть и отдельно живущие или часто отсутствующие, но не теряющие связь, доверие, проявляющие периодически внимание и заботу о менее активных близких.

Но особенно показательны наблюдения и самонаблюдения среди людей, недавно приобщившихся к информационно-технологическому пространству, - они довольно резко преобразовывают свой обиход, как неосознанно, так и целенаправленно.

Изменяется пищевой выбор (даже у людей, не обнаруживающих принципиальной позиции в этом направлении, заметно движение от сдобной, обработанной пищи - к более полезным видам, орехам и фруктам, овощам, расширяется применение пряностей, экзотических для данной местности и привычного обихода продуктов, приближённых к органическому питанию, появляются непривычные ранее способы приготовления пищи и темпоральные аспекты пищевого поведения), облегчается кашель, особенно связанный с нарушением метаболизма, улучшается осанка $[9,10]$.

Мелкомоторный праксис, активизируясь, улучшает точность движений общего плана, вкус к двигательной активности, инициирует целенаправленное здоровьесбережение.

Повышается готовность к общению, чувство юмора, сопереживания, восстанавливаются культурные и гигиенические привычки.

Такая тенденция просматривается как в целостном формате исследования, так и по нозологическим группам, по тяжести состояния, по дефицитарным позициям и поведенческим отклонениям [11].

Как утрата и огрубление, перверсии жизненных навыков, так и ресурсные достижения, могут быть диагностически интерпретированы и, в дальнейшем, служить для более точной подстройки сопровождающих мероприятий.

Конечно, представленная картина не исключает совпадения социального выбора и эффективности праксиса с индивидуальной предрасположенностью и микросоциальными запросами, готовностью близких активно способствовать благоприятствованию в данном и иных направлениях жизнедеятельности [12], но полного совпадения и даже преобладающего соответствия мы здесь не обнаружили.

Таким образом, университеты пожилого возраста - это необходимо и замечательно, но изучение популяционных изменений $[13,14]$, типологии и вариаций освоения цифрового пространства, разработки целевых программ для различных групп населения являются задачами ближайшей перспективы.

\section{Литература}

[1] Рыбакова Е.В, Рыбаков Д.Г., Султанова Р.М., Гаязова Г.А.. Механизмы развития информационного иммунитета современного человека. - Материалы международной научно-практической конференции Наука сегодня: проблемы и пути решения, Вологда, 28 марта 2018 г.;

[2] Рыбакова Е.В., Султанова Р.М., Гаязова Г.А.. Демотивация разума. Компонентный анализ трендового мышления. LAP Lambert Academic Publishing, Саарбрюккен 2016;

[3] Рыбаков Д.Г., Рыбакова Е.В., Мустафина Д.М. Информационные технологии и новая философия общения. Организация интернет-гостиной в формате межведомственного межрегионального сотрудничества социально ориентированных служб и общественных организаций. - Материалы IX международной научно-практической конференции "Россия и Европа: связь культуры и экономики" Прага, World Press 2014;

[4] Рыбаков Д.Г., Рыбакова Е.В., Султанова Р.М., Гаязова Г.А. Inheritance discompetention. - Science Time May, 2016;

International Culture \& Technology Studies, Vol. 4, No. 1 
[5] Султанова P.М., Гаязова Г.А., Рыбаков Д.Г., Рыбакова Е.В.. Клиника одиночества. Доктор Джекилл и мистер Xayc? - PSYCHOLOGY OF THE 21ST CENTURY: THEORY, PRACTICE, PROSPECT Materials of the VIIinternational scientific conference on February 15, Vědecko vydavatelské centrum ,«Sociosféra», 2017;

[6] Рыбаков Д.Г. Синхронизация глобальных ИТ-процессов и современных социально-образовательных вызовов. - Материалы Х Международной конференции "Фундаментальные и прикладные исследования в современном мире", Санкт-Петербург 2015;

[7] Рыбакова Е.В., Рыбаков Д.Г., Султанова Р.М., Гаязова Г.А., Акубекова Г.Д., Резяпов Р.А. Коррелирующие позиции информационного развития социума и нейропсихического состояния подрастающих поколений. - Материалы VIII международной научно-практической конференции "Образование: традиции и инновации", Прага, World Press 201

[8] Рыбакова Е.В., Султанова P.M, Гаязова Г.А.. MODULING OF CONTACT WITH OF CHILDREN WITH ASD AND MANIFESTATIONS OF NEGATIVISM DIDACTIC. - Материалы VII международной научнопрактической конференции "Образование: традиции и инновации", Прага, World Press, 2015;

[9] Султанова Р.М., Гаязова Г.А., Рыбакова Е.B.. Vertical effect. Modern researches, electronic edithing, 2017;

[10] Rybakova E. V., Rybakov Dmitry Gennadievich, Sultanova Roza Minayakhmetovna, Gayazova Gulshat Anifovna Manifestations of sociogenesis and didactogenesis in psychosomatic disorders [Электронный pecypc] // Interregional Interagency Internet Lounge "Belaja Rjech". 2017; https://belajarjech.nethouse.ru/articles/349193 (дата обращения: 28.05.2017);

[11] Rybakova E.V. Tiphlotolerance in inclusive education. - Science and Education, October 30-31, 2013;

[12]Рыбаков Д.Г., Рыбакова Е.В.. Неотолерантность как новая реальность общественной жизни и антикризисный ресурс. - Международная научно-практическая конференция «Стратегическое антикризисное управление: глобальные вызовы и роль государства». - Москва, МГУ, 2016;

[13]Рыбакова Е.В.. Геронтологический договор как темпоральная форма регуляции отношений между поколениями. - Материалы Национального конкурса «Золотая Психея», 2009г.;

[14] Рыбакова Е.В, Султанова Р.М., Гаязова Г.А., Рыбаков Д. Г..Диалоговое мышление как современный продукт эволюции когнитивной функции человека. - журнал СПВ pedagogical-views, июль 2018.

\title{
The impact of digital communications on quality of life, life satisfaction and a sense of inclusion of older people
}

\author{
E.V. Rybakova, R.M. Sultanova, G.A. Gajazova
}

Bashkir State University, Russia

\begin{abstract}
The well-being of the oldest generations of the population and, accordingly, an increase and harmonization of their productive contribution to the life of society, minimizing the risks and negative impact of unresolved problems on all participants in the social space requires a timely study of the realities, needs and prospects of their existence and needs. For many of them, livelihoods seem to be independent of the increasing informatization, many insist on excluding this aspect of scientific and technological progress from their employment. However, it is not only that technologies can provide comfort and increase efficiency in all spheres of a person's life, even less socially active, less mobile, distanced. Studies conducted in the Republic of Bashkortostan on the basis of scientific, educational, public organizations show that the digitization of the human environment reflects not only the needs of knowledge, business and culture. The systematic deployment of Internet technologies correlates with the development of all mankind as a whole, and to remain independent of the information movement of the world, both in a broad sense and in the technological context, is ineffective and, accordingly, inefficient, uncomfortable, even if the classical plan is as favorable as possible.
\end{abstract}

Keywords: inclusiveness, elderly, livelihoods, technology, satisfaction

\section{References}

[1] Rybakova E.V, Rybakov D.G., Sultanova R.M., Gajazova G.A.. Mehanizmy razvitija informacionnogo immuniteta sovremennogo cheloveka [Mechanisms for the development of information immunity of modern man]. - Materialy mezhdunarodnoj nauchno-prakticheskoj konferencii Nauka segodnja: problemy i puti reshenija, Vologda, 28 marta 2018 g..

[2] Rybakova E.V., Sultanova R.M., Gajazova G.A.. Demotivacija razuma. Komponentnyj analiz trendovogo myshlenija [Demotivation of the mind. Component analysis of trend thinking]. LAP Lambert Academic Publishing, Saarbrjukken 2016; 17-23 p.

Культура и технологии, Том 4, № 1 
[3] Rybakov D.G., Rybakova E.V., Mustafina D.M. (2014). Informacionnye tehnologii i novaja filosofija obshhenija. Organizacija internet-gostinoj v formate mezhvedomstvennogo mezhregional'nogo sotrudnichestva social'no orientirovannyh sluzhb i obshhestvennyh organizacij [Information technology and new communication philosophy. Organization of an Internet lounge in the format of interdepartmental interregional cooperation of socially oriented services and public organizations.]. - Materialy IX mezhdunarodnoj nauchnoprakticheskoj konferencii "Rossija i Evropa: svjaz' kul'tury i jekonomiki" - Praga, World Press.

[4] Rybakov D.G., Rybakova E.V., Sultanova R.M., Gajazova G.A. Inheritance discompetention. - Science Time May, 2016.

[5] Sultanova R.M., Gajazova G.A., Rybakov D.G., Rybakova E.V.. Klinika odinochestva. Doktor Dzhekill i mister Haus? [Clinic of loneliness. Dr. Jekyll and Mr. House?] - PSYCHOLOGY OF THE 21ST CENTURY: THEORY, PRACTICE, PROSPECT Materials of the VIIinternational scientific conference on February 15, Vědecko vydavatelské centrum, «Sociosféra», 2017.

[6] Rybakov D.G. (2015) Sinhronizacija global'nyh IT-processov i sovremennyh social'no-obrazovatel'nyh vyzovov [Synchronization of global IT processes and modern social and educational challenges.]. - Materialy X Mezhdunarodnoj konferencii "Fundamental'nye i prikladnye issledovanija $v$ sovremennom mire" [Proceedings of the X International Conference "Fundamental and Applied Research in the Modern World"], Sankt-Peterburg.

[7] Rybakova E.V., Rybakov D.G., Sultanova R.M., Gajazova G.A., Akubekova G.D., Rezjapov R.A. Korrelirujushhie pozicii informacionnogo razvitija sociuma i nejropsihicheskogo sostojanija podrastajushhih pokolenij [Correlated positions of informational development of society and the neuropsychic state of the younger generations]. - Materialy VIII mezhdunarodnoj nauchno-prakticheskoj konferencii "Obrazovanie: tradicii i innovacii" [Proceedings of the VIII International Scientific and Practical Conference "Education: Tradition and Innovation",], Praga. World Press 201.

[8] Rybakova E.V., Sultanova R.M, Gajazova G.A.. MODULING OF CONTACT WITH OF CHILDREN WITH ASD AND MANIFESTATIONS OF NEGATIVISM DIDACTIC. - Materialy VII mezhdunarodnoj nauchnoprakticheskoj konferencii "Obrazovanie: tradicii i innovacii" [Proceedings of the VII International Scientific and Practical Conference "Education: Tradition and Innovation"]. Praga, World Press, 2015.

[9] Sultanova R.M., Gajazova G.A., Rybakova E.V.. Vertical effect. Modern researches, electronic edithing, 2017.

[10] Rybakova E. V., Rybakov Dmitry Gennadievich, Sultanova Roza Minayakhmetovna, Gayazova Gulshat Anifovna Manifestations of sociogenesis and didactogenesis in psychosomatic disorders . Available at // Interregional Interagency Internet Lounge "Belaja Rjech". 2017. https://belajarjech.nethouse.ru/articles/349193 (Accessed date: 28/4/2011: 28.05.2017).

[11] Rybakova E.V. Tiphlotolerance in inclusive education. - Science and Education, October 30-31, 2013.

[12] Rybakov D.G., Rybakova E.V.. Neotolerantnost' kak novaja real'nost' obshhestvennoj zhizni i antikrizisnyj resurs [Neotolerance as a new reality of public life and anti-crisis resource.]. - Mezhdunarodnaja nauchnoprakticheskaja konferencija «Strategicheskoe antikrizisnoe upravlenie: global'nye vyzovy i rol' gosudarstva» [International Scientific and Practical Conference "Strategic crisis management: global challenges and the role of the state."]. - Moskva, MGU, 2016.

[13] Rybakova E.V.. Gerontologicheskij dogovor kak temporal'naja forma reguljacii otnoshenij mezhdu pokolenijami [Gerontological agreement as a temporal form of regulation of relations between generations]. Materials of the National Competition "Golden Psyche» [Materials of the National Competition "Golden Psyche»]. Available at: https://psy.su/psyche/projects/270/ (Accessed date: 14/06/2019).

[14] Rybakova E.V, Sultanova R.M., Gajazova G.A., Rybakov D. G. (июль 2018). Dialogovoe myshlenie kak sovremennyj produkt jevoljucii kognitivnoj funkcii cheloveka [Interactive thinking as a modern product of the evolution of human cognitive function]. - zhurnal SPV pedagogical-views [zhurnal SPV pedagogical-views], июль 2018. 